\title{
Restrictive endocardial fibroelastosis in a neonate without other cardiac pathology
}

\author{
D J Farrell, J R Skinner
}

\begin{abstract}
A case is presented of constrictive endocardial fibroelastosis without other cardiac abnormality in a newborn infant who was treated successfully by orthotopic heart transplantation.
\end{abstract}

(F Clin Pathol 1992;45:1042-1043)

Endocardial fibroelastosis (EFE) with ventricular constriction is generally associated with other cardiac pathology, most commonly hypoplastic left heart syndrome or ventricular outflow obstruction.

When not accompanied by other abnormalities, EFE is usually associated with ventricular dilatation. ${ }^{2}$ We present a case of constrictive EFE without other cardiac abnormality in a newborn infant who was successfully treated by orthotopic heart transplantation.

\section{Case report}

A six week old male infant born at term and weighing $3.2 \mathrm{~kg}$ presented with feeding difficulties and vomiting. On examination there were obvious clinical signs of heart failure but he was not cyanosed while breathing air. There were no dysmorphic features. An echocardiogram revealed concordant venous and arterial connections. There was a very small, poorly contracting left ventricle with a bright and strongly thickened endocardium; the left atrium was hugely dilated (fig 1). The mitral and aortic valves, the ascending aorta, and aortic arch looked normal. There was a very low left ventricular output and the systemic circulation was mostly supplied through a large patent ductus arteriosus.

Over a few days he deteriorated, requiring ventilation and inotropic support. At 7 weeks of age palliative surgery was performed: the left atrium was decompressed by atrial septectomy and pulmonary blood flow regulated by banding of the branch pulmonary arteries. Patency of the arterial duct was maintained by prostaglandin infusion.

At 10 weeks of age he underwent an uneventful orthotopic heart transplantation and at 12 months of age was alive and well.

\section{Pathological findings}

The recipient heart was submitted for pathological examination. Macroscopic examination showed a globular heart weighing $36 \mathrm{~g}$ com-
Department of Histopathology, Freeman Hospital, Newcastle upon Tyne D J Farrell

Department of Paediatric Cardiology, Freeman Hospital, Newcastle upon Tyne J R Skinner

Correspondence to: Dr D J Farrell, Department of Histopathology, Royal Victoria Infirmary, Queen Victoria Road, Newcastle upon Tyne NE1 4LP.

Accepted for publication 28 April 1992

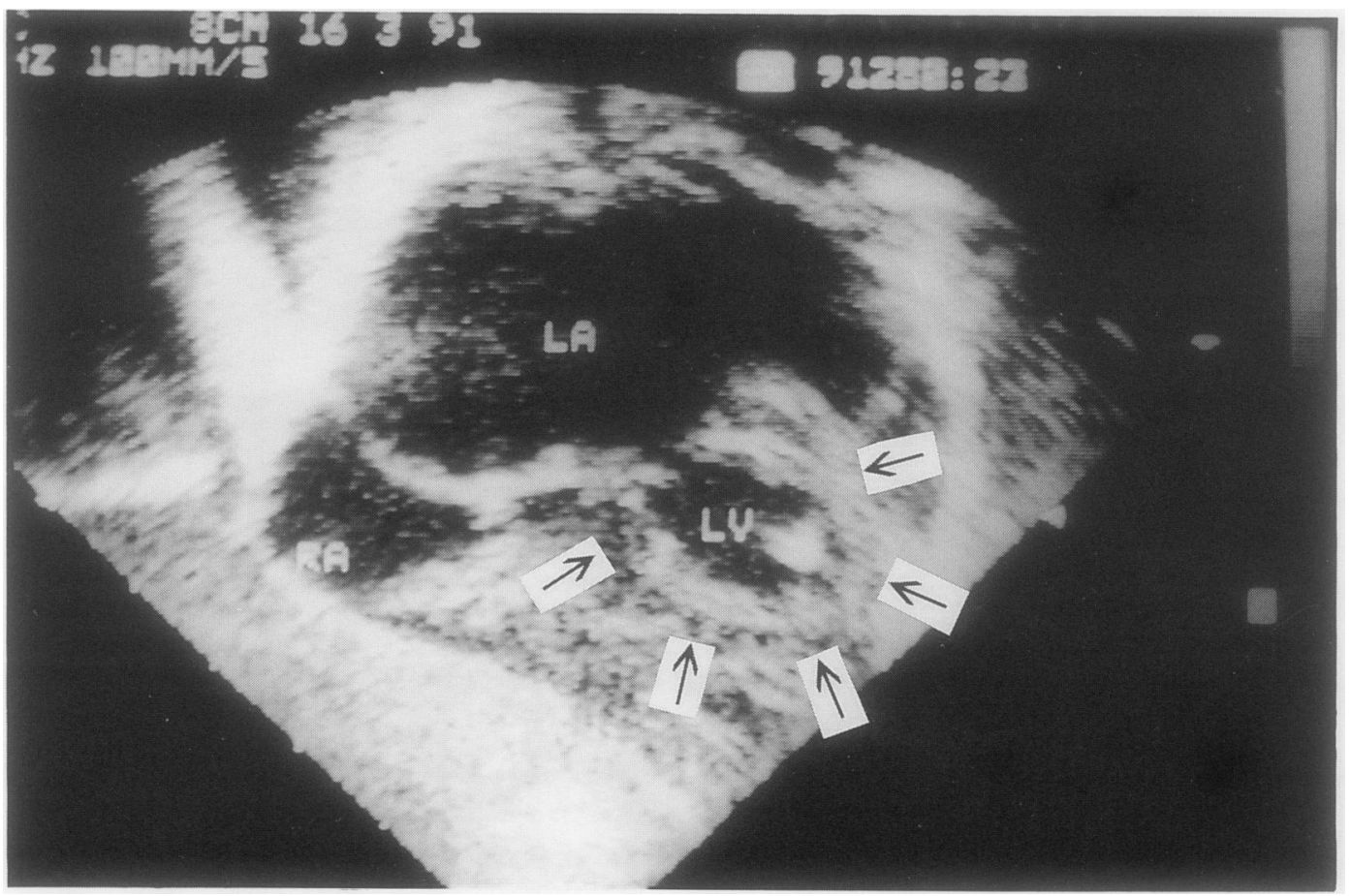

Figure 1 Subcostal cross-sectional echocardiographic view of the heart. $(L A=$ left atrium, $R A=$ right atrium, LV left ventricle). There is gross dilatation of the left atrium. The arrows outline the diminutive left ventricle. 

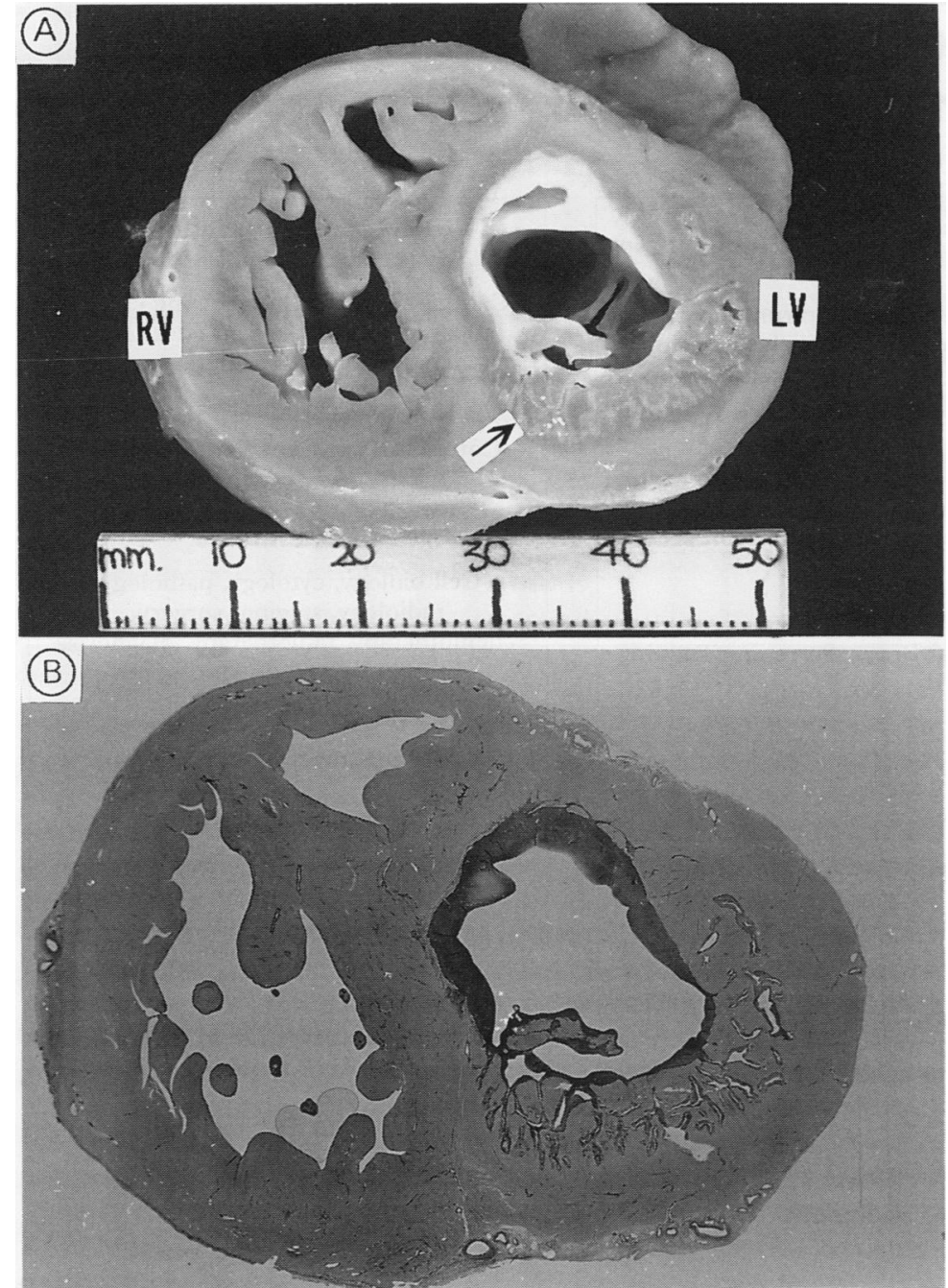

Figure $2(A) \quad(L V=$ left ventricle, $R V=$ right ventricle) The endocardium of the left ventricle is grossly thickened and has a white porcelain appearance. The thickened endocardium extends into the sinusoids of the myocardium (arrow). (B) The thickened endocardium is composed of parallel bands of collagen and elastic fibres (elastic van Gieson stain).
The thickened endocardium was composed of parallel bundles of collagen and elastic fibres and extended into the sinusoids of the underlying myocardium which also showed foci of dystrophic calcification. The myocytes were hypertrophic.

\section{Discussion}

Endocardial fibroelastosis has been described in association with a variety of cardiac and other abnormalities ${ }^{1-5}$ However, a proportion of cases without other pathology were formerly classified as "primary EFE". Most of these tended to be of the dilated type and the constrictive form of EFE is usually associated with clinically important left ventricular outflow tract obstruction or other major cardiac malformation.

The aetiology and pathogenesis of all forms of EFE remain obscure. It has been suggested that if the left ventricle is regarded as a modified muscular artery, the changes which occur in EFE are similar to those seen in muscular arteries damaged by hypertension. ${ }^{3}$ Clearly, in this patient chronic left ventricular hypertension cannot be the reason and the fact that isolated constrictive EFE can occur supports the suggestion that EFE is not a specific condition but rather the pathological result of many different diseases. ${ }^{\circ}$ In other words, there is no "primary EFE" because all EFE is the end stage of some reactive or inflammatory process in the endocardium or myocardium. Endocardial smooth muscle cells, normally few in number, proliferate and undergo a transition to fibroblasts producing both collagen and elastin. ${ }^{7}$ The cause of this smooth muscle cell proliferation is unknown but it may be a reaction to myocarditis or a genetic myocardial defect during fetal or early post natal life. ${ }^{\circ}$

prising the left and right ventricles with a $1 \mathrm{~cm}$ rim of left and right atria. The endocardium in all chambers was thickened and white. This was most pronounced in the left ventricular cavity where the endocardium had a porcelain appearance and measured up to $0.3 \mathrm{~cm}$ in thickness. In places the endocardium could be seen lining clefts, which extended into the underlying myocardium (fig $2 \mathrm{~A}$ ). The chamber of the left ventricle was small and was half the size of the right ventricular chamber, although the myocardium of both ventricles was hypertrophied. The tricuspid, mitral, aortic and pulmonary valves were normal. The left and right coronary arteries arose normally from the aorta.

Microscopic examination showed thickening of the endocardium in all chambers but was most pronounced in the left ventricle (fig 2B).
We acknowledge the advice and comments of Drs $\mathrm{S}$ Hunter and H Bain, and we thank Mrs L Parker for typing the manuscript. Dr Skinner was supported by the national heart research fund.

1 McKinney B. Endocardial fibroelastosis. In: Pathology of the Cardiomyopathies. London: Butterworths 1974:11-28.

2 Ursell PC, Neill CA, Anderson RH, Ho SY, Becker AE, Gerlis LM. Endocardial fibroelastosis and hypoplasia of the left ventricle in neonates without significant aortic stenosis. Br Heart $\mathcal{F} 1984 ; 51: 492-7$.

3 Newbould MJ, Armstrong GR, Barson AJ. Endocardial fibroelastosis in infants with hydrops fetalis. $\mathcal{F}$ Clin Pathol fibroelastosis in

4 Angelov A, Kulova A, Gurdevsky H. Endocardial fibroelastosis. Clinico-pathological study of 38 cases. Pathol Res Pract 1984;178:384-8. saccharidosis I presenting with endocardial fibroelastosis of infancy. Am $\mathcal{f}$ Dis Child 1989;143:782-4.

6 Lurie PR. Endocardial fibroelastosis is not a disease. $A m \mathcal{F}$ Cardiol 1988;62:468-70.

7 Newstein HG, Lurie PR, Fugita M. Endocardial fibroelastosis found on transvascular endomyocardial biopsy in children. Arch Pathol Lab Med 1979;103:214-19.
5 Stephan MJ, Stevens GL, Wenstrup RJ, et al. Mucopoly- 